Karl F. Hampl MD, Markus C. Schneider MD, Urban Rüttimann MD, Wolfgang Ummenhofer MD, Jürgen Drewe MD

\title{
Perioperative administration of caffeine tablets for prevention of post- operative headaches
}

Internuption of daily caffeine consumption can cause caffeine withdrawal headache. As headache ranks among the most frequent minor postoperative sequelae, the impact of perioperative substitution of caffeine on the incidence of postoperative headache was evaluated. Forty patients undergoing minor surgical procedures with general anaesthesia were randomly allocated to receive either placebo or caffeine tablets at a dosage equal to their individual average daily caffeine consumption. Daily dietary intake was calculated based on an average weekday consumption using conversion factors from previously published sources. The patients were instructed at the preoperative visit to abstain from all external sources of caffeine. Compliance with these dietary restrictions was verified by blood samples obtained immediately before the surgical procedure and on postoperative day 1. The patients were assessed for headache using a standardised checklist immediately before induction of anaesthesia, on the evening of the day of surgery and on the morning of postoperative day 1. Ten patients (50\%) who received placebo reported headaches, which persisted in seven patients (35\%) until the next day. No patient receiving caffeine substitution therapy reported headache following surgen, and only one complained of headache on postoperative day 1 . We suggest that the prophylactic administration of caffeine tablets might be considered for surgical patients who are accustomed to a high daily intake of caffeine.

Linterruption de lingestion quotidienne de caféine peut provoquer de la céphalée par suppression. Comme la céphalée constitue une séquelle pastopératoire très fréquente, lïmpact

\section{Key words}

COMPLICATIONS: headaches;

PHARMACOLOGY: caffeine.

From the Department of Anaesthesia, University of Basel/ Kantonsspital, CH-4031 Basel, Switzerland.

Address correspondence to: Dr. Karl F. Hampl, Department of Anaesthesia, University of Basel/Kantonsspital, $\mathrm{CH}-4031$

Basel, Switzerland.

Accepted for publication 30 April, 1995. du retrait de la caféine sur lincidence postopératoire de la céphalée est évalué. Quarante patients soumis à une chirurgie mineure sous anesthésie générale sont répartis au hasard pour recevoir soit un placebo soit une dose de caféine en tablette équivalente à leur ingestion quotidienne. Lingestion quotidienne est calculée sur la base de la consommation moyenne d'une journée modifiée avec un facteur de conversion tiré de publications antérieures. Lors de la visite préopératoire, les patients sont avisés d'éviter la caféine sous toutes ses formes. L'adhésion à ces restrictions est vérifiée par des échantillons de sang prélevés immédiatement avant lintervention et la journée qui suit. L'évaluation de la céphalée est effectuée avec une formule standardisée avant linduction, le soir de la chirurgie et le matin de la journée suivante. Dix patients (50\%) qui ont reçu le placebo ont rapporté des céphalées, qui ont. persisté chez sept patients (35\%) jusqu'au lendemain. Aucun de ceux qui ont reçu le substitut ne s'est plaint de céphalée immédiatement après la chirurgie, et un seul s'en est plaint le lendemain. Nous suggérons d'administrer préventivement des tablettes de caféine aux patients habitués à une consommation quotidienne élevée de caféine.

Interruption of caffeine intake can cause a withdrawal syndrome characterised by headache, fatigue, drowsiness, irritability and, in some instances, nausea and vomiting. ${ }^{1-3}$ However, headache is not only the primary symptom of caffeine withdrawal but it also represents one of the most frequent postoperative complaints following general anaesthesia. ${ }^{4}$ Previously, postoperative headache was attributed solely to side effects related to general anaesthesia. Yet, as a large proportion of surgical patients may be used to consuming large amounts of caffeine ${ }^{5}$ and must fast before elective anaesthesia, caffeine withdrawal may contribute to postoperative headache in some patients. $^{6-8}$ The purpose of the present prospective, double-blind, placebo-controlled study was to evaluate whether prophylactic perioperative administration of caffeine tablets may affect the incidence of postoperative headache. 


\section{Methods}

With institutional approval and written informed consent, 40 patients scheduled for minor surgical procedures with general anaesthesia were studied. Criteria for eligibility included: 20 to $65 \mathrm{yr}$; ASA-Class I or II; considerable daily caffeine intake ( $\geq 200 \mathrm{mg}$ per day); no history of frequent headaches ( $\geq$ once a week); non-smokers; non current medical treatment; no surgical procedure involving the head or neck; surgery between 8:00 and 10:00 a.m. The patients were instructed to abstain from all external sources of caffeine intake, including chocolate, cocoa and decaffeinated coffee or decaffeinated tea from the time of the preoperative visit (approximately 16-18 $\mathrm{hr}$ preoperatively).

Compliance with these dietary restrictions was verified by analysis of blood samples obtained during the surgical procedure and on postoperative day 1 . The samples were frozen and stored for subsequent analysis of caffeine by gas chromatography.

The patients were randomly allocated into one of two study groups: Group C (caffeine) received caffeine tablets at a dosage equal to their individual average daily caffeine consumption and Group $P$ received placebo. The individual daily dietary consumption of caffeine was calculated based on an average weekday consumption using caffeine-level factors from previously published sources. ${ }^{10}$ One half of the calculated dose was given at the time of premedication, the other half at 3 p.m. of the day of the operation. This dose was repeated at 7.00 a.m. on postoperative day 1 .

Both caffeine and placebo tablets with identical appearance were made by the pharmacy of the University of Basel. An anaesthetist, who did not take part in the intraoperative management and the perioperative assessments of the patients, placed the tablets in blinded vials according to the allocation; then, these vials were given to a ward nurse who administered the study drugs.

The patients were premedicated with midazolam 7.5 mg po one hour before surgery. Following preoxygenation, anaesthesia was induced using thiopentone 5 $\mathrm{mg} \cdot \mathrm{kg}^{-1}$ and fentanyl $1 \mu \mathrm{g} \cdot \mathrm{kg}^{-1}$ followed by succinylcholine $1 \mathrm{mg} \cdot \mathrm{kg}^{-1} \dot{\boldsymbol{v}}$ to facilitate orotracheal intubation. Anaesthesia was maintained with $66 \%$ nitrous oxide in oxygen and isoflurane as needed. Postoperative analgesia was standardised (paracetamol 500 to $1000 \mathrm{mg}$ po and/ or methadone $\left(0.1 \mathrm{mg} \cdot \mathrm{kg}^{-1} \mathrm{im}\right)$. The total amount of analgesics received during the postoperative period was recorded.

Following orotracheal intubation, a \#18 French gastric tube was advanced orally $60-70 \mathrm{~cm}$ past the incisors. Correct position was confirmed as recommended by auscultation over the stomach while air was inserted or by aspiration of typical gastric content. ${ }^{9}$ The gastric tube was then withdrawn and rotated with intermittent aspiration using a $50 \mathrm{ml}$ syringe. ${ }^{9}$ The volume of fluid was recorded, and its $\mathrm{pH}$ measured using a calibrated $\mathrm{pH}$ meter (pH-Meter 632, Methrom AG, Herisau, Switzerland).

Patients were repetitively assessed for symptoms of caffeine withdrawal by an anaesthetist unaware of the study drugs and details of the anaesthetic or surgical procedure. These examinations were performed on the morning of surgery immediately before induction of anaesthesia; at approximately $6 \mathrm{p} . \mathrm{m}$. on the evening following surgery and on the morning of the first postoperative day. To assure a standardised data collection a comprehensive checklist was used. The patients were explicitly asked by the examining anaesthetist if they suffered from headache, nausea, vomiting, fatigue or unsteadiness. They were also asked whether they had consumed any beverages or food containing caffeine.

Demographic data and dosages of caffeine and analgesics were compared using ANOVA; the incidence of postoperative side effects was analysed using the $\chi^{2}$-test. The level of statistical significance used was $P<0.05$.

\section{Results}

Demographic data and mean daily caffeine intake were not different between the study groups (Table I). There were no differences in the duration or type of surgery (Table II) and the total amount of postoperative analgesic requirement among the study groups (Table III). No patient consumed any caffeine-containing beverages during the study period as evidenced by the plasma caffeine levels (Table IV). There were no differences in the volume or $\mathrm{pH}$ of the aspirated gastric fluid (Table IV).

The incidences of postoperative side effects are summarised in Table V. There was a higher proportion of patients reporting headache in Group $P$ than in Group $\mathrm{C}$ on both postoperative visits, but no differences in frequencies of other symptoms of caffeine withdrawal. There were no correlations between the incidences of postoperative headaches and age, sex, or type and duration of the surgical procedure.

\section{Discussion}

Caffeine is the most widely used behaviourally active drug in the world. In the United Statess and Canada, daily per capita caffeine consumption has been estimated to be 211 and $238 \mathrm{mg}$, respectively. ${ }^{1}$ Abrupt cessation of daily caffeine consumption may result in a syndrome which is characterised by headache, fatigue, nausea, and irritability, the most consistent symptom being headache. ${ }^{1-3}$ Headache from caffeine withdrawal has been observed in individuals with a daily caffeine intake of as little as $100 \mathrm{mg},{ }^{11}$ the equivalent of about one cup of 
TABLE I Patient characteristics and daily caffeine intake. There were no differences between the groups. All data represent mean \pm SD

\begin{tabular}{lcc}
\hline & $\begin{array}{c}\text { Caffeine } \\
(n=20)\end{array}$ & $\begin{array}{l}\text { Placebo } \\
(n=20)\end{array}$ \\
\hline Age (yr) & $47.2 \pm 16.8$ & $48.4 \pm 19.6$ \\
(range) & $(22-61)$ & $(18-55)$ \\
Weight (kg) & $66.8 \pm 13.0$ & $74.9 \pm 14.4$ \\
Height (cm) & $165.7 \pm 8.9$ & $168.1 \pm 9.2$ \\
Sex (M/F) & $6 / 14$ & $7 / 13$ \\
Daily caffeine intake (mg) & $430 \pm 143.6$ & $380 \pm 168.9$ \\
\hline
\end{tabular}

TABLE II Duration of surgery (mean \pm SD) and type of surgical procedures (number of patients)

\begin{tabular}{lcll}
\hline & $\begin{array}{c}\text { Caffeine } \\
(n=20)\end{array}$ & $\begin{array}{l}\text { Placebo } \\
(n=20)\end{array}$ & \\
\hline Duration of surgery (min) & $63 \pm 48$ & $79 \pm 42$ & NS \\
Plastic/reconstructive & 3 & 7 & NS \\
Orthopaedic upper extremity & 6 & 3 & NS \\
Orthopaedic lower extremity & 5 & 8 & NS \\
Gynaecological & 6 & 2 & NS \\
\hline
\end{tabular}

TABLE III Postoperative analgesic requirement. There were no differences between the groups. All data represent mean \pm SD

\begin{tabular}{lcc}
\hline & \multicolumn{1}{c}{ Caffeine } & \multicolumn{1}{l}{ Placebo } \\
\hline Paracetamol (mg) & & \\
- Operation day & $850 \pm 235$ & $750 \pm 265$ \\
- Postoperative day 1 & $\frac{825 \pm 293}{1675 \pm 440}$ & $\frac{700 \pm 300}{1450 \pm 470}$ \\
- Total & & \\
Methadone (mg) & $4.8 \pm 3.2$ & $5.4 \pm 4.1$ \\
- Operation day & 0 & 0 \\
- Postoperative day 1 & $\frac{0}{4.8 \pm 3.2}$ & $5.4 \pm 4.1$ \\
- Total & & \\
\hline
\end{tabular}

coffee, two cups of tea or $700 \mathrm{ml}$ of cola soft drinks. ${ }^{10}$ Headache may occur as early as eight hours after the last caffeine consumption," while objective evidence (electromyographic alterations) of caffeine withdrawal can be present after only three hours of abstinence. ${ }^{12}$ As the risk of postoperative headache is increased in patients accustomed to a high daily caffeine consumption, ${ }^{6-8}$ the possibility of caffeine withdrawal syndrome should be taken into account in patients suffering from headaches, especially if they are placed in caffeine-free wards.

Although postoperative ingestion of caffeine-containing beverages has been shown to reduce the incidence of postoperative headache, ${ }^{8}$ the effectiveness of prophylactic perioperative administration of caffeine has not been evaluated. In the present study, prophylactic perioperative substitution of caffeine resulted in a highly significant
TABLE IV Gastric fluid analysis and plasma caffeine levels. All data represent mean $\pm S D$

\begin{tabular}{|c|c|c|c|}
\hline & Caffeine & Placebo & \\
\hline $\begin{array}{l}\text { Gastric fluid volume (ml) } \\
\text { (range) }\end{array}$ & $\begin{array}{l}19.2 \pm 14.6 \\
(0-38)\end{array}$ & $\begin{array}{l}22.7 \pm 11.9 \\
(0-33)\end{array}$ & NS \\
\hline Gastric fluid $\mathrm{pH}$ & $2.12 \pm 1.63$ & $1.91 \pm 1.24$ & NS \\
\hline \multicolumn{4}{|l|}{$\begin{array}{l}\text { Plasma caffeine levels } \\
\left(\mathrm{mg} \cdot \mathrm{ml}^{-1}\right)\end{array}$} \\
\hline - Preoperative & $2.2 \pm 1.8$ & $0.2 \pm 0.15$ & $P<0.001$ \\
\hline - Postoperative day 1 & $2.9 \pm 2.3$ & 0 & $P<0.001$ \\
\hline
\end{tabular}

TABLE V Incidence of side effects

\begin{tabular}{llll}
\hline & $\begin{array}{c}\text { Caffeine } \\
(n=20)\end{array}$ & $\begin{array}{l}\text { Placebo } \\
(n=20)\end{array}$ \\
\hline Preoperative & & & \\
- Headache & 0 & 1 & NS \\
- Nausea & 0 & 0 & \\
- Vomiting $>2)$ & 0 & 0 & \\
- Fatigue & 1 & 3 & NS \\
- Unsteadiness & 4 & 2 & NS \\
& & & \\
6 p.m. Day of operation & & & \\
- Headache & 0 & 10 & $P<0.001$ \\
- Nausea & 4 & 7 & NS \\
- Vomiting $>2)$ & 3 & 5 & NS \\
- Fatigue & 7 & 4 & NS \\
- Unsteadiness & 1 & 0 & NS \\
& & & \\
9 a.m. Postoperative day 1 & & & \\
- Headache & 1 & 7 & $P<0.05$ \\
- Nausea & 0 & 4 & NS \\
- Vomiting $>2)$ & 0 & 0 & NS \\
- Fatigue & 1 & 1 & NS \\
- Unsteadiness & 0 & 0 & NS \\
\hline
\end{tabular}

reduction in the incidence of postoperative headaches. These findings are consistent with results obtained from several studies in volunteers in which double-blind administration of caffeine tablets reduced the incidence of caffeine withdrawal headache. ${ }^{11,13,14}$

Patients in both study groups had a mean daily caffeine intake of approximately $400 \mathrm{mg}$. Following placebo administration, headache was observed on the evening of the day of surgery and on the morning of postoperative day 1 with frequencies of $50 \%$ and $35 \%$, respectively. These numbers are in accordance with the incidence of headache observed in both volunteers ${ }^{13}$ and surgical outpatients ${ }^{6,7}$ with a comparable daily caffeine consumption.

Results from a recent study in volunteers provide strong evidence that caffeine withdrawal produces craving for caffeine beverages and foods, which may result in 
an increased probability of caffeine self-administration. ${ }^{15}$ A recent study in surgical outpatients found that $12 \%$ of patients reported to have consumed caffeinated beverages on the morning of surgery despite explicit instructions to fast. ${ }^{6}$ Thus, the administration of caffeine tablets may not only reduce the craving for caffeine ${ }^{16}$ but also improve patients' compliance of perioperative fasting.

Caffeine stimulates gastric acid secretion. ${ }^{17}$ Therefore, preoperative administration of caffeine might increase the risk of aspiration of gastric content in surgical patients. However, the stimulatory effect of caffeine on gastric acid secretion is dose-dependent with a threshold plasma caffeine level of about $5 \mathrm{mg} \cdot \mathrm{L}^{-1}{ }^{18}$ Since caffeine substitution therapy resulted in much lower pre- and postoperative caffeine plasma levels than this threshold (Table IV), it was not unexpected that we were unable to demonstrate an increased gastric secretion in these patients compared with those receiving placebo. We note that caffeine plasma levels in our patients receiving caffeine were comparable with those measured in outpatients not subjected to any restrictions of caffeine intake. ${ }^{5}$

We believe that the results of our study have several clinical implications. First, the data support previous speculations on caffeine withdrawal being partially responsible for postoperative headache. ${ }^{6-8}$ Second, in patients with a high daily caffeine intake and a history suggestive of caffeine withdrawal headaches, perioperative caffeine substitution should be considered in order to reduced the incidence of postoperative headache and to improve patients' compliance in following fasting guidelines. Finally, our findings indicate that such a policy may also be an effective means of reducing costs linked to postoperative morbidity caused by unexplained headache. ${ }^{19}$

\section{References}

1 Griffiths $R R$, Woodson PP. Caffeine physical dependence: a review of human and laboratory animal studies. Psychopharmacology (Berl) 1988; 94: 437-51.

2 Smith $R$. Caffeine withdrawal headache. J Clin Pharm Ther 1987; 12: 53-7.

3 Greden JF, Victor BS, Fontaine P, Lubetsky M. Caffeinewithdrawal headache: a clinical profile. Psychosomatics 1980; 21 : 411-8.

$4 \mathrm{Ogg} T W$. An assessment of postoperative outpatient cases. BMJ 1972; 840: 573-6.

5 Smith J, Pearson S, Marks $V$. Plasma caffeine concentrations in outpatients (Letter). Lancet 1982; 2: 985-6.

6 Fennelly $M$, Galletly $D C$, Purdie GI. Is caffeine withdrawal the mechanism of postoperative headache? Anesth Analg 1991; 72: 449-53.

7 Galletly DC, Fennelly M, Whitwam JG. Does caffeine withdrawal contribute to postanaesthetic morbidity? (Letter). Lancet 1989; 1: 1335.

8 Weber JG, Ereth $M H$, Danielson DR. Perioperative ingestion of caffeine and postoperative headache. Mayo Clin Proc 1993; 68: 842-5.

9 Søreide E, Søreide JA, Holst-Larsen H, Steen PA. Studies of gastric content: comparison of two methods. $\mathrm{Br} \mathrm{J}$ Anaesth 1993; 70: 360-2.

10 Rall TW. Central nervous system stimulants. In: Gilman AG, Goodman LS, Rall TW, Murad F (Eds.). The Pharmacological Basis of Therapeutics, 7th ed. New York: Macmillan Publishing, 1985: 589-603.

11 Griffiths RR, Evans SM, Heishman SJ, et al. Low-dose caffeine physical dependence in humans. J Pharmacol Exp Ther 1990; 255: 1123-32.

12 White BC, Lincoln CA, Pearce NW, Reeb $R$, Vaida $C$. Anxiety and muscle tension as a consequence of caffeine withdrawal. Science 1980; 209: 1547-8.

13 Silverman K, Evans SM, Strain EC, Griffiths RR. Withdrawal syndrome after double-blind cessation of caffeine consumption. N Engl J Med 1992; 327: 1109-14.

14 Greden JF. Anxiety or caffeinism: a diagnostic dilemma. Am J Psychiatry 1974; 131: 1089-92

15 Griffiths $R R$, Woodson PP. Reinforcing effects of caffeine in humans. J Pharmacol Exp Ther 1988; 246: 21-9.

16 Griffiths RR, Evans SM, Heishman SJ, et al. Low-dose caffeine discrimination in humans. J Pharmacol Exp Ther 1990; 252: 970-8.

17 Curatolo $P W$, Robertson $D$. The health consequences of caffeine. Ann Intern Med 1983; 98: 641-53.

18 Debas HT, Cohen MM, Holubitsky IB, Harrison RC. Caffeine-stimulated acid and pepsin secretion: doseresponse studies. Scand J Gastroenterol 1971; 6: 453-7.

19 Hampl KF, Stotz G, Schneider MC. Postoperative transient hemihypaesthesia and severe headache associated with caffeine withdrawal (Letter). Anaesthesia 1994; 49: 266-7. 